\title{
Tradução científica, tradução cultural, tradução poética
}

\author{
A málio Pinheiro
}

Parece-me que a relação entre as obras - para não ser meramente acumulativa e seqüencial, mas produtiva e reativa - pode ser medida pelo crivo das operações tradutórias, dentro de um percurso crítico que enfeixasse desde as questões lingüísticas trazidas pelas grandes revoluções científicas e culturais até aquelas surgidas do contágio entre linguagens distintas e entre os menores elementos dentro de cada texto. O nó górdio é poder dar a obra conta da contaminação entre os quatro estágios: o científico, o cultural, o que se dá entre as diversas e cada vez mais proliferantes séries artístico-comunicacionais e aquele que se plasma na massa intersígnica específica de um dado texto.

O primeiro deles é bem desdobrado por Thomas Kuhn. Ao separar os avanços científicos "normais", aqueles em que lentamente se elaboram por proximidade analógica os substitutos metafóricos familiares a uma mesma comunidade científica, daqueles chamados revolucionários, que "põem em jogo descobertas que não podem acomodar-se dentro dos conceitos que eram habituais antes de que se fizessem ditas descobertas"(1), traz de modo crucial à baila novas implicações e complicações da tarefa tradutória.

Resumindo abruptamente a teoria de Kuhn, chamam-nos a atenção suas duas espécies de tradução. A primeira, chamada de tradução propriamente dita, serve aos casos em que não tenha havido uma brusca modificação no modo de estruturar a relação entre a linguagem e os referentes: "Vamos dizer simplesmente que o texto traduzido conta mais ou menos a mesma história, que apresenta mais ou menos as mesmas idéias, ou que descreve mais ou menos a mesma situação que o texto do qual é uma tradução (...) Naturalmente, pode ter aumentado o número de referentes conhecidos de um dado termo, mas não foi alterado o modo como esses referentes, antigos e novos, se determinam (...) A tradução consiste só em palavras e frases que substituem (não necessariamente uma a uma) palavras e frases do original"(2). A este primeiro tipo kuhniano equivale (se o aplicarmos ao território da tradução poética) a descartável tradução literal, que ignora as mudanças reativas exigidas pelo transplante para a concretude da língua de chegada, detendo-se dentro de um fácil mecanismo metafórico de substituições por similitude semântica abstraídas do mosaico reagente de significações.

Para algo mais interessante aponta a segunda espécie de Kuhn, chamada de "interpretação", reservada para os casos em que a homologia estrutural entre as línguas não resolve a "incomensurabilidade" entre a nova revolução científica e as comunidades cientíticas e lingüísticas em vigor. Agora se fazem necessários dois requisitos. Em primeiro lugar, é fundamental observar o caráter holístico dos termos a serem traduzidos: “'Esta é a razão de que a 'força' e a 'massa' newtonianas não sejam traduzíveis à linguagem de uma teoria física (aristotélica ou einsteniana, por exemplo) que não utiliza a versão de Newton da segunda lei. Para se apreender qualquer destes três modos de fazer mecânica, os termos inter-relacionados em alguma parte local da rede da linguagem devem ser apreendidos ou reapreendidos simultaneamente, e aplicados em seguida à
AMÁLIO PINHEIRO é professor do Programa de Comunicação e Semiótica da PUC-SP, tradutor e autor de César Vallejo: o abalo corpográfico e Vallejo a dedo (ambos pela Arte Pau-Brasil).
1 Thomas S. Kuhn, Qué son las revoluciones cientfficas? y otros ensayos, Barcelona, Paidós, 1989, p. 59.

2 Idem, ibidem, pp. 103-4.

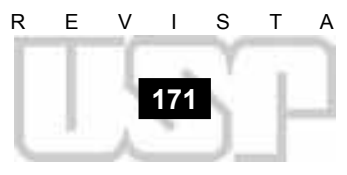




\section{O moderníssimo luri}

Tinianov foi o precursor, entre os formalistas,

ao mostrar... que a

"qualidade diferencial"

a ser percebida num

"fato literário" é

a sua "correlação

seja com a série

literária, seja com uma

série extraliterária". Quem

traduz não pode perder de

vista desde os

menores movimentos

significantes aos grandes

planos temáticos Kuhn se sirva apenas, para pesar a comunicabilidade das revoluções na ciência, do plano do significado na rede de linguagem a ser traduzida).

O acima exposto aponta para o fato de que os sistemas filosóficos, que entram em interações variadas com os sistemas tecnológico-cientifficos mais radicais, podem ser traduzidos pelos intérpretes-tradutores da cultura, entre os quais o tradutor poético é uma espécie radicalíssima (que coloca em ação "todos" os planos reativo-operativos da linguagem dentro de cada novo bolsão de espaço e tempo). Podemos assim compreender melhor a frase com que Bachelard inaugura o seu "Prefácio" à Filosofia do Não: "A utilização dos sistemas filosóficos em domínios afastados da sua origem espiritual é sempre uma operação delicada, muitas vezes uma operação falaciosa. Assim transplantados, os sistemas filosóficos tornam-se estéreis ou enganadores; perdem a sua eficácia de coerência espiritual, eficácia tão sensível quando são revividos na sua originalidade real com a fidelidade escrupulosa do historiador, e perde-se também a satisfação de pensar o que nunca será pensado duas vezes. Será pois necessário concluir que um sistema filosófico não deve ser utilizado para outros fins para além dos que ele se atribui"'(5). Compreende-se também melhor uma insistente advertência de Borges às traduções alemãs das Mil e uma noites: "Há maravilhas nas Noites que eu gostaria de ver repensadas em alemão (...) $\mathrm{O}$ que não faria um homem, um Kafka, que organizasse e acentuasse esses jogos, que os refizesse segundo a deformação alemã, segundo a Unheimlichkeit da Alemanha?"(6). E o moderníssimo Iuri Tinianov foi um precursor entre os formalistas, ao mostrar, na mesma linha, analisando a mobilidade paródico-intertextual da literatura, que a "qualidade diferencial" a ser percebida num "fato literário" é a sua "correlação seja com a série literária, seja com uma série extraliterária"(7). Quem traduz não pode perder de vista, desde os menores movimentos significantes aos grandes planos temáticos, essa necessidade de montar uma discórdia operativa a partir do novo enquadramento lingüŕstico-cientifico-cultural em que se inclui cada obra. Como anunciava o mesmo Tinianov: "O sistema da série literária é antes de tudo o sistema das funções da série literária que se encontra em relação ininterrupta com as outras séries. As séries mudam nos seus componentes mas a diferenciação das atividades humanas permanece. A evolução literária, como também a evolução das outras séries culturais, não coincide nem no seu ritmo nem no seu caráter (por causa da especificidade 


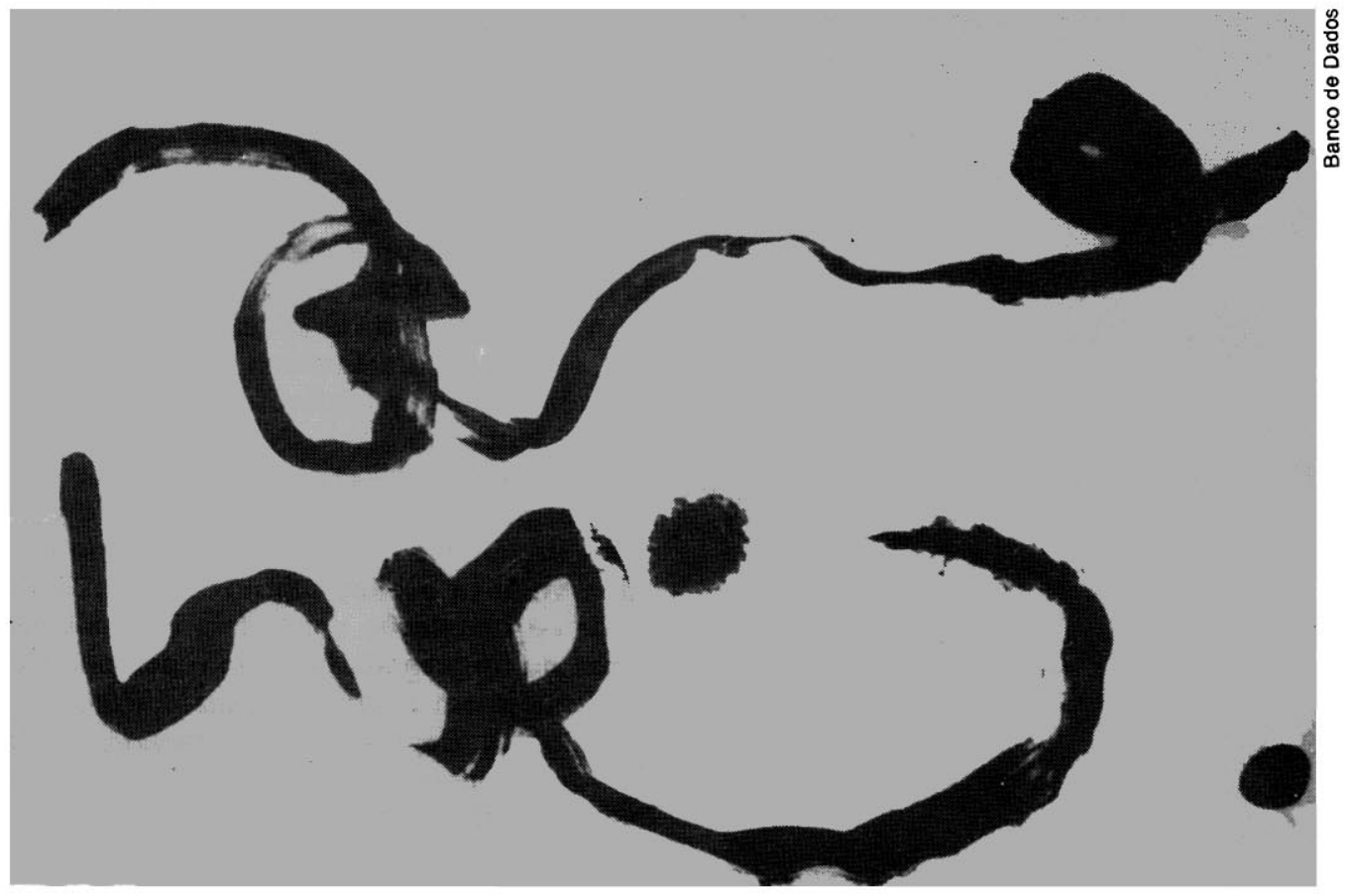

do material que maneja) com as séries correlatas"(8). Já poderíamos daqui em diante iniciar um diálogo crítico com aquelas traduções poéticas que, embora inimigas naturais da literalidade, esgrimem as absolutamente necessárias reconstruções formais sem impregná-las da saudável e intransponível descontinuidade temporal-espacial entre os textos, optando antes por uma sorte de redistribuição lúdica na direção regressiva das marcas logocêntricas, ainda que em expansão produtiva, da origem do original.

Se fosse possível, a partir do diálogo com Kuhn, conjugar as idéias contidas nessas trases de Bachelard, Borges e Tinianov, eu diria que um tradutor-transcriador não pode eximir-se de embutir em todos os planos interativos do material traduzido o modo como as revoluções científicas vieram e vêm sendo traduzidas pelas coordenadas culturais múltiplas e convergentes em que se embebe a língua de chegada. Dou um pequeno exemplo, tirado das amostras de Sérgio Buarque de Holanda, sobre a transição tradutória colossal realizada entre duas etapas científicas antes grandemente dissociadas no tempo e no espaço: “... não custa desde já apontar para um dos motivos aparentes do bom sucesso da gente de São Paulo neste particular, comparado à atrofia que sofreu a expansão castelhana, depois do ímpeto inicial. Ou seja, para a aptidão maior que os primeiros revelaram no absorver e no conservar certos recursos indígenas, mormente os de locomoção à distância, e no rejeitar técnicas menos rudimentares, não raro, mas também menos aptas a superar os muitos embaraços opostos ao seu avanço"(9). Isso quer dizer que a série de inventos, como armas, meios de locomoção e navegação, etc., saídos da expansão do mundo europeu e renascentista em crescimento contínuo, tinham aqui sido readaptados, para efeitos de tradução científico-civilizatória (a interpretação kuhniana), conforme o aparato local de linguagens e muito provavelmente conforme, juntamente, os influxos arábigo-ibéricos trazidos já dos muitos séculos de convivência peninsular. Tudo isso implica uma noção, queira-se ou não, de história, técnica e ciência não-esférico-galilaicas e não-eurocêntricas, que o tradutor atento (da ciência, da cultura, da poesia) pode ao menos indiciar, realçar, desdobrar. Leia-se, entre muitos outros casos e exemplos, R. Rashed: "A atenuação da oposição entre ciência e arte parece de verdade ser a obra do conjunto das correntes intelectuais do período árabe (...) Em resumo, um conhecimento pode a partir de então ser científico sem que se conforme nenı ao esquema aristotélico nem ao esquema euclidiano"(10).

$\mathrm{O}$ tradutor de um texto poético tem de fazer as suturas, desde os elementos semânticos aos grafemáticos, entre ciência e cultura, que a própria língua já pode configurar como tradução (diz Severo Sarduy: "Quando o falar cubano se agita, há sempre várias línguas (várias civilizações) que se expõem, e o centro não está em parte alguma")(11). Só assım consegue o ato tradutório enfrentar a tensão sígnico-interpretativa provocada
Palavra do poeta, óleo sobre tela do pintor catalão Joan Miró, 1968
8 Idem, ibidem, pp. 53-4.

9 Sérgio Buarque de Holanda, $O$ extremo oeste, Săo Paulo, Brasiliense, 1986 , p. 49.

10 Rashed Rashed, "La Notion de Science Occidentale" in Entre Arithmétique et Aigebre - Recherches sur l'Histoire Les Belles Lettres, 1984, p. 314.

11 Severo Sarduy, Barroco, Lisboa, Ve ga, 1988, p. 11. Cit. por José Manuel de Vasconcelos. 


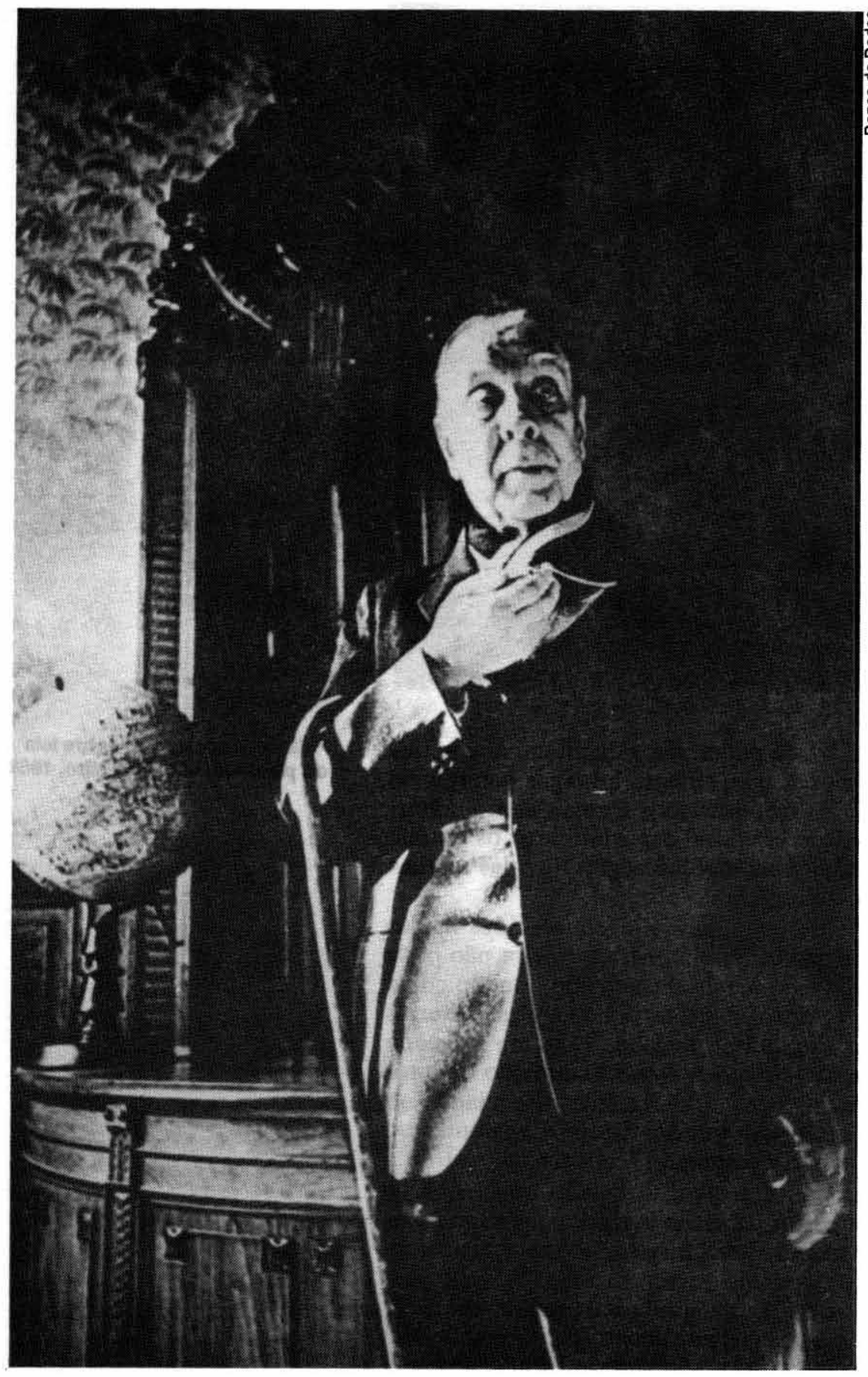

O escritor argentino Jorge Luis Borges pela colisão entre as grandes revoluçōes científicas de Kuhn e o leque de abalos lingüístico-culturais que, segundo Tinianov, a série literária põe em ação. Diz este último: "A evolução da função construtiva é que atua rapidamente; aquela da função literária é produzida de uma época a outra; aquela de toda a série literária, em relação às séries vizinhas, necessita de séculos'(12). São esses séculos de afastamento e deslocamento que têm de ser reconhecidos e impressos, lance a lance.

Não há tradução se o que vier de fora não reagir, por sua vez, sobre todo o conjunto lingüístico em que entrou, como uma pilha voltaica acelerando novas conexões a partir da imantação entre dois ou mais sistemas de linguagem. Quando o peruano César Vallejo em Trilce XIII, diz: "Pienso en tu sexo"; e depois: "Oh estruendo mudo. I iOdumodneurtse!', está pondo em sintonia mundos textuais de diversa extração histórico-geográfica, que pedem ação tradutória. O par /s/ e /x/ faz repercutir sonoramente o conflito entre cabeça e corpo, dilema filosófico aristotelizante aqui exposto de maneira direta e debochadamente coloquial-jornalística: "Pienso en tu sexo". Reparem-se também nas inserções naturais das rimas toantes internas e no ritmo binário das paroxítonas, que acentuam a cadência e marcam a não-gratuidade das relações entre as séries vizinhas (coloquial, oral, telegráfico-jornalística) e a urdidura do próprio verso (série poética). A implosão do verso final, que reescreve o penúltimo ao revés, explode consigo as conhecidas dualidades conceptistas herdadas do Siglo de Oro e o dilema entre o alto e o baixo da tradição metafísica. Os elementos composicionais aprendidos com o meio jornalístico (mobilidade gráfico-espacial e gráfico-visual, velocidade e corte telegráficos, etc.) são exponenciados e ao mesmo tempo reacomodados pela sonoridade, rimas, metro, etc., que revelam a nova postura auditiva do poeta, estridente e disrítmica, frente à herança lírica em voga. Seria possível a um tradutor desprezar essa luta sonora contra os esquemas vigentes de dominação política do ouvido através do verso? E mais: poderia deixar passar em branco a sua refuncionalização conforme a situação evolutiva do verso à época da última tradução e conforme os efeitos similares de luta desdobráveis pelo universo científico, cultural e lingüístico do idioma tradutor? 